\title{
Repercussão do grupo da coluna sobre o cotidiano de mulheres que apresentam dores musculoesqueléticas crônicas ${ }^{1}$
}

\author{
Adriane Vieira $^{\mathrm{a}}$, Patrícia Thurow Bartz ${ }^{\mathrm{b}}$, Márcia Cardoso da Jornada ${ }^{\mathrm{b}}$ \\ aDepartamento de Educação Física, Universidade Federal do Rio Grande do Sul - UFRGS, Porto Alegre, RS, Brasil.

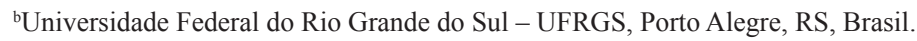

\begin{abstract}
Resumo: Introdução: As dores musculoesqueléticas crônicas têm impacto sobre a vida das pessoas, podendo desencadear diminuição da qualidade de vida. Políticas nacionais de atenção à saúde propostas nos últimos anos visam garantir a execução de estratégias educativas que promovam saúde e qualidade de vida de usuários do Sistema Único de Saúde (SUS). O projeto Grupo da Coluna no contexto do SUS é oferecido como alternativa de educação em saúde aos usuários com dores musculoesqueléticas crônicas. Objetivo: Conhecer a repercussão do Grupo da Coluna sobre o cotidiano de mulheres participantes do projeto. Método: O estudo foi qualitativo de ordem interpretativa, e o instrumento utilizado para coleta de dados foi a entrevista semiestruturada. Participaram da pesquisa nove mulheres. As entrevistas foram gravadas, transcritas, lidas e analisadas, sendo agrupadas em unidades de significado e posteriormente em duas unidades temáticas. Resultados: O Grupo da Coluna possibilitou às participantes um maior entendimento de suas limitações funcionais e serviu de estímulo para incorporação de uma postura mais adequada e de exercícios que evitem a recorrência de dores musculoesqueléticas. O Grupo também propiciou, segundo as participantes do estudo, um ambiente de acolhimento e interação social. Conclusão: O Grupo da Coluna contribuiu para que as usuárias mudassem seus hábitos e conseguissem relacionar a dor a aspectos psicológicos e a hábitos inadequados.
\end{abstract}

Palavras-chave: Dor Crônica, Atenção Primária à Saúde, Educação em Saúde, Qualidade de Vida, Humanização da Assistência.

\section{Impact of back group on everyday life of women presenting chronic musculoskeletal pain}

\begin{abstract}
Introduction: Chronic musculoskeletal pain impacts people's lives, triggering a decrease in the quality of life. National health Policies proposed in recent years have aimed to ensure the implementation of educational strategies that promote health and quality of life for users of the Unified Health System (SUS). The Back Group project is offered by the SUS as alternative health care education for users with chronic musculoskeletal pain. Objective: To ascertain the day-to-day impact of the Back Group on women participants in the project. Method: A qualitative study of an interpretive order. The instrument used for data collection was a semi-structured interview. Participants were nine women. Their statements were recorded, transcribed and analyzed, being grouped into two units of meaning and later according to thematic units. Results: The Back Group allowed participants to better understand their functional limitations and served to motivate them to incorporate more adequate posture and exercises that avoid the recurrence of musculoskeletal pain. According to study participants, the Group also provided a welcoming environment for social interaction. Conclusion: The Back Group contributed to users changing their habits, helping them to relate pain to psychological questions and poor habits.
\end{abstract}

Keywords: Chronic Pain, Primary Health Care, Health Education, Quality of Life, Humanization of Assistance.

Autor para correspondência: Adriane Vieira, Laboratório de Pesquisa do Exercício, Universidade Federal do Rio Grande do Sul, Rua Felizardo, 750, sala 218, Bairro Jardim Botânico, CEP 90690-200, Porto Alegre, RS, Brasil, e-mail: adriane.vieira@gmail.com

Recebido em Mar. 20, 2016; 1ª Revisão em Set. 12, 2016; 2ª Revisão em Dez. 19, 2016; Aceito em Fev. $21,2017$. 


\section{Introdução}

Devido à intensificação do processo de urbanização no Brasil, nas últimas cinco décadas, houve uma ampliação dos problemas relacionados à ocupaçáo desordenada, à diminuição das áreas verdes, à desigualdade na distribuição de riquezas, ao aumento da violência e à poluição atmosférica, sonora e visual. Somado a isso, vivemos em um tempo de revoluçáo tecnológica, mudanças nos processos de trabalho, inatividade física e envelhecimento da população. Esse contexto propicia um aumento de problemas crônicos de saúde, nos quais fatores como o estresse e o estilo de vida sedentário influenciam a qualidade de vida das pessoas, assim como mudam o perfil de doenças e agravos enfrentados pelos serviços de saúde (MORETTI et al., 2009).

Atualmente, o Brasil encontra-se em uma situação epidemiológica de dupla carga de doenças, pois, além das antigas doenças infectocontagiosas, está aumentando o desenvolvimento de doenças e agravos não transmissíveis relacionados a condiçôes de cronicidade, como diabetes, doenças relacionadas ao aparelho circulatório e respiratório e câncer (MENDES, 2012). O estudo de Moretti et al. (2009), realizado em Sáo Paulo, mostra que esta segunda classe de doenças é responsável por $76 \%$ da mortalidade geral, $63 \%$ das internaçôes pagas e 73\% dos gastos do Sistema Único de Saúde (SUS) por internações. Estas doenças geram altos custos com tratamento e reabilitaçáo e repercutem na situação econômica do país.

As dores musculoesqueléticas, especialmente na coluna lombar, são um dos agravos não transmissíveis mais comuns enfrentados pela população ocidental (BALAGUÉ et al., 2012). A dor nas costas pode ser desencadeada por diversos fatores, entretanto, a maior parte nấo tem causa conhecida (CHOU et al., 2007). A etiologia da dor nas costas pode estar relacionada a variáveis demográficas e psicossociais, precárias condições de vida e saúde, estilo de vida, falta de acesso às informaçôes e uso incorreto da mecânica corporal no trabalho ou lar (ARCANJO; VALDÉS; SILVA, 2008).

Quando a dor se torna crônica, as queixas podem interferir significativamente na qualidade de vida das pessoas. A perda da capacidade funcional é uma delas e acomete o desempenho de atividades de vida diária (AVDs) (ALVES et al., 2007). Essa perda está relacionada tanto às limitaçóes geradas pela presença da dor, quanto ao medo que a execução de AVDs possa agravar o problema, levando a um círculo vicioso de perda de condicionamento físico, desesperança, imagem corporal alterada e baixa autoestima (LIRA; NATIONS; CATRIB, 2004). $\mathrm{O}$ cotidiano do indivíduo, revelado por sua rede de relaçóes sociais, organização do trabalho e da vida privada, atividades costumeiras de autocuidado, tarefas domésticas, lazer e descanso (GALHEIGO, 2003), pode ser modificado em decorrência de um quadro crônico que transforma atividades anteriormente realizadas com facilidade em desafios e demanda novas aprendizagens (SALLES; MATSUKURA, 2013). Portanto, ao abordar a dor musculoesquelética crônica, não é suficiente conhecer e tratar a queixa de dor como um elemento que independe das açóes da pessoa no mundo, é preciso investigar tanto de que maneira ela interfere no cotidiano das pessoas, quanto de que maneira as açóes do cotidiano acabam repercutindo na queixa de dor.

É previsto pela Política Nacional de Atenção Básica (PNAB) a implementaçáo de programas de educação e promoção da saúde que visem desenvolver uma atenção integral que impacte na situação de saúde e autonomia das pessoas e atendam às necessidades de saúde de maior frequência e relevância no território (BRASIL, 2012), sendo a dor lombar um destes problemas, de acordo com a Pesquisa Nacional de Amostras de Domicílio (PNAD) realizada no Brasil em 2008 (BRASIL, 2010).

Os programas de educação em saúde devem ser compostos por atividades dirigidas à conquista da autonomia, nas quais se valorize a construção conjunta de conhecimento que possam melhorar as condiçóes de vida e colaborar para a transformação dos comportamentos de risco passíveis de mudanças que estariam, pelo menos em parte, sob o controle dos próprios indivíduos (SILVA-ARIOLI et al., 2013). Diferentes profissionais como fisioterapeutas, terapeutas ocupacionais, psicólogos, professores de educação física, médicos e enfermeiros podem ser protagonistas desses programas em serviços de atenção básica à saúde, atuando individualmente ou em equipes multiprofissionais nas ações de educação em saúde direcionadas a usuários que apresentam dores crônicas (BRASIL, 2014a).

Um dos focos centrais na abordagem de programas de educação em saúde para usuários com dores crônicas são os hábitos posturais inadequados, que podem ser incluídos nos comportamentos de risco passíveis de mudanças, visto que o mau uso da mecânica corporal nas atividades de vida diária pode gerar sobrecarga e disfunçôes no sistema musculoesquelético e acarretar dores e sensaçôes de mal-estar (FURTADO et al., 2009). No entanto, ainda há poucos estudos e documentos que avaliam a repercussão de propostas de educação em saúde voltadas para dor musculoesquelética crônica 
nos serviços de atençáo básica à saúde no Brasil (POLIZELLI; LEITE, 2010), sendo necessário pensar em propostas viáveis e ampliar a discussão e problematização da dor musculoesquelética como uma condição que demanda atenção dos serviços de saúde.

Em vários documentos direcionados ao cuidado integral de doenças crônicas não transmissíveis (BRASIL, 2008, 2011, 2013, 2014b), não encontramos dados ou diretrizes que orientem avaliação e tratamento das dores musculoesquelética crônicas. Realidade distinta à observada em outros países, como o Reino Unido, onde atenção e assistência a esse tipo de problema têm sido debatidas e intervençóes educativas são oferecidas aos usuários nos serviços de atenção básica (FERGUSON, 2010).

Propostas educativas que estimulem hábitos posturais adequados que podem evitar e amenizar problemas álgicos e processos degenerativos, bem como prevenir problemas cinético-funcionais (VIEIRA; SOUZA, 2002; MAUSS, 1974), devem ser inseridos na atenção básica em saúde. No entanto, além de a dor crônica ser um problema pouco considerado, a principal estratégia que tem sido utilizada pelos serviços de saúde no Brasil é a medicalização, que, segundo Tesser (2006), leva a uma perda do potencial cultural para manejo da maior parte das situaçóes de dor, adoecimento e sofrimento. O medicamento alivia os sintomas, mas não acolhe o sofrimento $\mathrm{e}$ não informa as possíveis causas da dor ou educa o usuário sobre formas de amenizar ou administrar o problema.

Considerando a importância de propostas educativas, o projeto de extensão Grupo da Coluna, tendo por referência a Escola Postural, foi criado em 2009 para atender usuários que sofrem de dor musculoesquelética crônica em uma Unidade Básica de Saúde (UBS) de Porto Alegre, Rio Grande do Sul. A Escola Postural é uma intervenção educativa em grupo proposta pela fisioterapeuta sueca Mariane Zachrisson-Forssell na década de 1970 e difundida no Brasil a partir da década de 1990 (NOLL et al., 2014). Na atualidade, há diferentes propostas de escola postural em relação ao número de encontros e de participantes, assim como de profissionais que ministram os encontros, mas elas têm em comum o objetivo de explicar a anatomia da coluna e multidimensionalidade de causas da dor crônica, possibilitar uma troca de experiências entre os participantes, ensinar exercícios básicos para melhora da força, flexibilidade e relaxamento e propiciar a vivência de posturas adequadas para facilitar a realização de AVD (NOLL et al., 2014).
O projeto Grupo da Coluna foi estruturado em cinco encontros e teve como objetivo amenizar os problemas enfrentados por mulheres que lidam com a perda de funcionalidade e qualidade de vida devido a um quadro de dor persistente, com uma abordagem que levou em consideração as estratégias propostas pela Escola Postural e os fatores biopsicossociais que influenciam a postura e as dores musculoesqueléticas crônicas.

Este estudo faz parte de um projeto de pesquisa mais amplo, que buscou entender as repercussóes do Grupo da Coluna e, em artigo que avaliou os seus efeitos a partir de análise quantitativa, identificamos uma diminuição significativa na intensidade das dores, na limitaçáo funcional imposta pela dor, assim como uma melhora da qualidade de vida (BORGES et al., 2011). Apesar da importância dos resultados apresentados no estudo de Borges et al. (2011), consideramos também relevante conhecer questóes subjetivas relacionadas à dor e as percepçóes das participantes acerca das atividades desenvolvidas em aula. Tínhamos interesse em compreender se as atividades teóricas e práticas trabalhadas nos encontros do Grupo da Coluna foram relacionadas com mudanças de postura, comportamentos e redução $\mathrm{da}$ dor em atividades desenvolvidas em suas rotinas diárias. Portanto, neste estudo, que corresponde a uma segunda etapa do projeto de pesquisa, visamos, a partir de uma pesquisa qualitativa, conhecer a repercussão do Grupo da Coluna no cotidiano das mulheres.

\section{Método}

Este estudo apresenta uma abordagem qualitativa de viés interpretativo, a qual se caracteriza pela compreensáo e pela valorização das interpretaçóes de pessoas sobre uma determinada situação (MINAYO, 2010). Segundo André (1983), através de estudos qualitativos é possível compreender o caráter multidimensional dos fenômenos em sua manifestação natural, bem como captar os diferentes significados de uma experiência vivida, auxiliando a compreensão do indivíduo no seu contexto. Este estudo foi apreciado e aprovado pelo Comitê de Ética em Pesquisa do Hospital de Clínicas de Porto Alegre (n¹00354).

O instrumento utilizado para coleta de informações foi a entrevista semiestruturada (MINAYO, 2010). Utilizamos um roteiro de perguntas baseado na tese de doutorado de Vieira (2004), que abordava a dor, a postura e as percepçóes em relação aos encontros do Grupo da Coluna, permitindo às participantes relatar suas experiências e expressar temas e questóes que 
consideravam mais relevantes. A questão norteadora da entrevista foi: "Qual a influência do Grupo da Coluna no seu cotidiano?".

As participantes que compareceram a pelo menos três encontros dos cinco que compóem o Grupo da Coluna foram convidadas, após finalização dos encontros, a participar do estudo. Aquelas que aceitaram o convite compareceram à Unidade Básica de Saúde em dia e horário agendados. As entrevistas foram realizadas em sala apropriada (somente com a presença da pesquisadora e participante do estudo), tiveram a duraçáo de meia hora a uma hora e foram gravadas e transcritas na íntegra. Todas as participantes leram e assinaram o Termo de Consentimento Livre e Esclarecido e receberam nomes fictícios para preservar sua identidade.

As informaçóes coletadas nas entrevistas foram transcritas e agrupadas em unidades de significado que surgiram da leitura minuciosa das transcrições, ou seja, as interpretações das falas obtidas nas entrevistas foram agrupadas a partir da convergência das informaçôes coletas, procurando ampliar a compreensão dos significados das experiências vividas pelas participantes do estudo. Os procedimentos para análise das informaçóes foram embasados em Giorgi (2008), sendo eles: (1) leitura inicial e ampla dos dados; (2) releitura para discriminação das unidades de significado com o foco no fenômeno que está sendo investigado; (3) exame, exploração e descrição das unidades de significado e (4) síntese das unidades de significado em função do fenômeno pesquisado, descrevendo a estrutura essencial da experiência vivida. Assim, após definir as unidades de significado, elas foram reescritas e organizadas em unidades temáticas, cuja descrição e interpretação contemplam as repercussóes das atividades desenvolvidas no Grupo da Coluna sobre o cotidiano das participantes.

Participaram deste estudo nove mulheres (Tabela 1) encaminhadas para o Grupo pelos médicos da equipe da Unidade Básica de Saúde onde o estudo foi desenvolvido. Elas tinham entre 42 e 68 anos, apresentavam dor musculoesquelética crônica na coluna lombar e algumas também em outras regióes corporais, e seis delas moravam sozinhas, sendo uma viúva e cinco solteiras. Além de realizarem as atividades domésticas em suas casas, seis das participantes também trabalhavam como empregadas domésticas, zeladoras e prestadoras de serviços de limpeza em condomínios residenciais, os quais thes demandam um esforço físico redobrado. Todas associavam a piora ou o surgimento da dor com a realização dessas atividades rotineiras, apresentando, portanto, limitaçóes em sua capacidade funcional.

O Grupo da Coluna foi estruturado em cinco encontros teórico-vivenciais com duração de duas horas, ministrados uma vez por semana em uma UBS de Porto Alegre e contemplando em cada edição de oito a doze usuárias. Os temas escolhidos para os encontros visaram proporcionar um momento de troca de experiências e de vivências que estimulassem a percepçáo de que hábitos posturais e comportamentos podem exacerbar ou amenizar a dor e o mal-estar. No primeiro encontro, enfatizávamos os aspectos mecânicos, psicológicos e socioculturais relacionados aos hábitos posturais; a relação entre dor, estado emocional, crenças e comportamento e a relevância do cuidado postural para autoadministração da dor. Esses aspectos eram relembrados e revistos nos demais encontros ao vivenciarmos atividades de vida diária, como, por exemplo, pegar objetos no chão, carregar objetos, dormir, permanecer sentado e em pé, varrer, trabalhar no computador, lavar louça. Em cada encontro trabalhávamos, aproximadamente, uma hora de atividades teórico-vivenciais e uma hora de exercícios de percepção corporal, alongamento, reforço muscular e de relaxamento, além de atividades de massagem e automassagem. Utilizávamos uma linguagem de fácil compreensão e o resgate de experiências do cotidiano dos participantes. Por fim,

Tabela 1. Descrição das participantes do estudo.

\begin{tabular}{|c|c|c|c|c|}
\hline Nome & Idade & Profissão & Escolaridade & Estado Civil \\
\hline Orquídea & 47 & Desempenha serviços domésticos e condominiais ${ }^{1}$ & Ensino Fundamental & Solteira \\
\hline Gérbera & 38 & Desempenha serviços domésticos e condominiais ${ }^{1}$ & Ensino Fundamental & Solteira \\
\hline Rosa & 43 & Desempenha serviços domésticos e condominiais ${ }^{1}$ & Ensino Fundamental & Solteira \\
\hline Violeta & 42 & Desempenha serviços domésticos e condominiais ${ }^{1}$ & Ensino Fundamental & Casada \\
\hline Hortência & 58 & Do lar & Ensino Fundamental & Solteira \\
\hline Acácia & 50 & Desempenha serviços domésticos e condominiais ${ }^{1}$ & Ensino Fundamental & Viúva \\
\hline Jasmim & 68 & Aposentada & Ensino Médio & Casada \\
\hline Margarida & 55 & Desempenha serviços domésticos e condominiais ${ }^{1}$ & Ensino Fundamental & Casada \\
\hline Gardênia & 42 & Funcionária Pública & Ensino Superior & Solteira \\
\hline
\end{tabular}

${ }^{1}$ As atividades inclusas nesse grupo de profissionais são empregadas domésticas, zeladoras e prestadoras de serviços de limpeza em condomínios residenciais. 
entregávamos folhetos que reforçavam as orientaçôes e os exercícios abordados nos encontros, servindo de estímulo para a realização desses em casa (Tabela 2). Os encontros foram ministrados pela professora coordenadora do projeto e por graduandos em fisioterapia e educação física.

\section{Resultados e Discussão}

A partir das falas das participantes nas entrevistas, foi possível identificar a presença de duas unidades temáticas que serão apresentadas a seguir: (1) incorporação de novos hábitos; (2) troca de experiências sobre o conviver com dor.

\subsection{Incorporação de novos hábitos}

A mudança de hábitos não ocorre de maneira momentânea, pois é necessário tempo, paciência e consciência do que se está realizando de forma inadequada, além de observação e compreensão do próprio corpo. Devido às repetiçôes de atividades rotineiras, os hábitos posturais acabam tornando-se automáticos, ou seja, os realizamos sem analisar se são adequados ou não. Para podermos mudar esse automatismo, é importante incorporar novas atitudes e identificar nossas dificuldades através da percepção do próprio corpo (VIEIRA, 2004). As intervençôes posturais podem ser meios facilitadores para incorporação de novos hábitos e comportamentos na execução de AVDs. Nas falas das participantes do estudo, essa incorporaçáo foi algo muito presente, sugerindo que os encontros do Grupo da Coluna contribuíram para que elas percebessem a relação que existe entre a dor e a maneira com que atividades rotineiras são realizadas:
O excesso de trabalho também me dava dor. Hoje eu divido o cesto de roupa, coloco o pé em cima do banquinho e quando termino de passar a roupa, termino sem dor (Rosa, 43 anos).

Hoje eu já me cuido mais, mas antes não, eu me abaixava de qualquer jeito. Porque se tu náo sabe a postura que tu tem que se comportar, tu fica pior ainda. Hoje, quando vou pegar um balde, eu já sei como me abaixar, como passar um pano, sei que tenho que cuidar a vassoura, todo o movimento que tenho que fazer. Ajuda um monte (Margarida, 55 anos).

Eu durmo com o travesseiro no meio das pernas, baixei o men travesseiro, eu troquei porque estava com muita dor na nuca, então deixei ele bem baixinho... eu deitava toda torta (Gérbera, 38 anos).

Há hábitos posturais inadequados que são automatizados e executados durante toda uma vida sem que se perceba a sua relação com a queixa e o mal-estar desencadeado pela atividade. Vem daí a importância de que as participantes do Grupo da Coluna percebessem seus padróes posturais e identificassem aqueles que poderiam agravar o desconforto, a fim de modificá-los, encontrando posturas mais adequadas às possibilidades pessoais e às exigências da tarefa. Era também preciso que soubessem escutar o seu corpo e que reconhecessem seus limites, tornando-se mais conscientes e autônomas na manutenção de sua saúde (ANDRADE; ARAÚJO; VILAR, 2005; SOUZA; VIEIRA, 2003; VIEIRA, 2008).

A compreensão de que a melhora da dor e do desconforto pode ocorrer através da mudança de hábitos é um acontecimento gradual (VIEIRA, 2004), que envolve a participação do indivíduo

Tabela 2. Atividades teóricas e práticas abordadas no Grupo da Coluna.

\begin{tabular}{ll}
\hline $1^{\text {o encontro }}$ & $\begin{array}{l}\text { Definição de postura e reflexão sobre a influência de aspectos biológicos, socioculturais e } \\
\text { psicológicos na incorporação de hábitos posturais. }\end{array}$ \\
\hline $2^{\text {o encontro }}$ & $\begin{array}{l}\text { Relações entre movimentos da coluna e membros inferiores na execução dos atos de sentar, } \\
\text { agachar e carregar objetos de forma mais adequada. }\end{array}$ \\
\hline $3^{\text {o encontro }}$ & $\begin{array}{l}\text { Noções básicas sobre estrutura e funcionalidade da coluna vertebral e manutenção das } \\
\text { posturas sentada e em pé. }\end{array}$ \\
\hline $4^{\circ}$ encontro & $\begin{array}{l}\text { Posicionamento e realização de atividades na posição deitada, posturas ao dormir e ato de } \\
\text { deitar e levantar da cama. }\end{array}$ \\
\hline $5^{\circ}$ encontro & Execução assistida e comentada de atividades de vida diária escolhidas pelos participantes. \\
\hline PRÁTICA \\
\hline Atividade lúdica no início de cada encontro. \\
\hline $\begin{array}{l}\text { Execução assistida e comentada das AVDs escolhidas em cada encontro e reforço da execução adequada das } \\
\text { AVDs dos encontros anteriores. }\end{array}$ \\
\hline $\begin{array}{l}\text { Exercícios de alongamento, fortalecimento, percepção corporal e relaxamento nas posições: sentada, em pé e } \\
\text { deitada. }\end{array}$ \\
\hline Automassagem e massagem feita pelas professoras.
\end{tabular}


no processo. Diferente do que acontece no manejo medicamentoso, que geralmente fornece uma resolução rápida e momentânea ao problema, a modificação dos hábitos envolve o entendimento que o indivíduo deve ser ativo no processo e corresponsável pela sua melhora. Essa participação do usuário já está bem documentada na literatura e é bastante recomendada nas diretrizes internacionais para manejo da dor crônica (AIRAKSINEN et al., 2006). Essa recomendação está em linha também com as indicações do Ministério da Saúde brasileiro na Política Nacional de Atenção Básica (BRASIL, 2012) e foi bastante estimulada no Grupo da Coluna.

Além do hábito postural, é preciso, muitas vezes, rever comportamentos que viabilizem a manutenção da função, apesar das limitações impostas pelo quadro de dor. O programa parece ter estimulado que algumas açôes fossem realizadas para esse fim, como pode ser observado nas falas de Hortência e Jasmim:

Antes eu ia ao super e trazia um monte de coisa. Agora eu vou e trago um pouquinho, depois en vou de novo e trago mais alguma coisa. Agora eu estou aprendendo! (Hortência, 58 anos).

A gente tem que cuidar da postura, não fazer movimento brusco, não exagerar, eu não tenho mais 18 anos, eu digo pra mim... calma, calma, vou me policiando né?! Antes eu estava sempre querendo correr mais que eu podia (Jasmim, 68 anos).

A troca de informaçóes e as experiências propiciadas pelo Grupo da Coluna contribuíram para que as participantes modificassem suas açóes no cotidiano, possibilitando-lhes gerir o cuidado de si (MACHADO et al., 2007), o que acreditamos ter contribuído para diminuição da dor, explicitada nas falas das participantes:

[a dor] Ta menos, né?! Porque eu não estou forçando de forma errada. Ela diminuiu por que eu mudei meu comportamento (Acácia, 50 anos).

A minha dor diminui bastante desde quando eu entrei para o Grupo (Rosa, 43 anos).

Mesmo quando eu tinha dor frequente eu não deixava de fazer certas coisas, mas agora eu nem falo em dor [...] Pra mim foi muito bom, grande diferença. Tu não vê mais eu me queixando de dor, toda vez que alguém ia à farmácia eu pedia pra me trazer um remédio (Margarida, 55 anos).

Ela [a dor] interferia bastante, a coisa que eu mais adoro é caminhar, e eu já estava deixando de fazer caminhada. Foi uma luz no fim do túnel, porque o que eu mais tinha medo era parar de caminhar, e agora eu sei que não vou parar de caminhar (Gardênia, 42 anos).
Agora melhorou. Antes ela interferia, não podia lavar um chão, claro que não vou ficar esfregando, mas eu consigo fazer as coisas [...] Agora eu consigo ler por mais tempo, porque agora eu coloco uma almofada nas costas e um apoio para os pés. Agora eu estou melhor (Hortência, 58 anos).

No estudo de Souza e Vieira (2003) e Arcanjo, Valdés e Silva (2008), que fazem uma análise qualitativa acerca das percepçóes de alunos que participaram de um programa de Escola Postural, os participantes comentaram que a dor ou o desconforto que sentiam anteriormente havia melhorado ou desaparecido depois de participar no programa. De maneira semelhante, as participantes no presente estudo também ressaltaram que o programa lhes ajudou a sentirem-se melhor, pela diminuiçáo da tensão muscular, através da mudança na maneira de realizar suas atividades de vida diária, e pela melhora na mobilidade articular. Além disso, um maior autocuidado e atenção aos movimentos rotineiros, o que lhes favoreceu a mudança dos hábitos posturais, também foi enfatizado pelas participantes.

Quando novas vivências são compreendidas e adquirem um significado para as participantes, elas tendem a ser internalizadas no dia a dia (ARCANJO; VALDÉS; SILVA, 2008; SOUZA; VIEIRA, 2003). O fato de perceberem que a mudança de hábito é capaz de propiciar uma redução da dor estimula a incorporação dessa mudança em ações rotineiras, aumentando a capacidade de gerenciamento do problema de saúde. Guedes, Silva e Silva (2007) realizaram estudo com um grupo de pessoas da terceira idade que possuíam alteraçóes posturais e dor, semelhante ao presente estudo, e constataram que a educação é a melhor forma de o indivíduo adquirir novos hábitos e aplicá-los nas atividades de vida diária.

\subsection{Troca de experiências sobre o conviver com dor}

Consideramos, a partir das falas das participantes, que os encontros do Grupo foram percebidos como um espaço de convivência que estimulou a troca de experiências comuns às participantes. Afirmaram, durante as entrevistas, que o Grupo possibilitou-lhes compartilhar angústias e solidarizar-se com os outros, fazendo com que as participantes se sentissem bem e amparadas:

Eu sou muito antissocial, en falo com outras pessoas, mas eu tenho que me socializar mais, é um momento bom vir aqui, espairecer e depois cada um vai pra sua casa (Acácia, 50 anos). 
Em grupo é muito bom, porque a gente vê os problemas da gente e dos outros e é bom pra gente aprender, tem que ser em grupo (Orquídea, 47 anos).

Parece que em grupo, com uma pessoa colocando o que sente, a outra também, dai você consegue perceber que não é só você que tem esse problema, eu acho que é bem melhor (Violeta, 42 anos).

Os relatos mostraram que trocar experiências boas e ruins relacionadas à vida e às dores com as outras participantes ajudaram a entender e enfrentar a sua condição. Warschauer (2008) constatou em seu estudo que o sentimento de participar de um grupo é intrínseco, pois estimula os participantes a aderirem ao projeto, fazendo com que se sintam confiantes e assim exponham seus problemas coletivamente e busquem soluçôes. Favoreto e Cabral (2009) desenvolveram seu estudo com um grupo de suporte oferecido para portadores de doenças crônico-degenerativas, como diabetes, hipertensão e obesidade. O grupo tem como objetivo desenvolver a autonomia, discutir e encontrar soluções para problemas que possam estar dificultando o tratamento, mostrando que, neste espaço dialógico, as pessoas trocavam experiências e se identificavam com os outros, o que também lhes ajudavam a entender suas próprias questóes. A convivência em espaços como estes, que promove uma rede de solidariedade e apoio, contribui para coletivizar a experiência do adoecimento, transformando experiências pessoais em experiências coletivas e possibilitando que o significado do adoecer não se restrinja ao de um castigo, uma ameaça, um fardo a ser solitariamente suportado. Além disso, a troca de experiências ajuda as pessoas a se capacitarem e serem mais autônomas sobre o modo de cuidar da sua saúde (FAVORETO; CABRAL, 2009).

A narrativa das participantes mostrou ainda que elas passaram a fazer relaçóes dos seus sintomas, dores e desconfortos com aspectos de suas vidas, sentimentos. As participantes se tornaram capazes de integrar as sensaçóes físicas que sentiam com os sentimentos pelos quais estavam passando, o que pode ser observado pelas seguintes falas:

Nos dias que eu estou mais alegre, eu não tenho tanta dor, e nos dias que eu estou com algum problema, ou está acontecendo alguma coisa com a minha filha ou o meu marido, então eu noto que no dia seguinte eu fico com muita dor. Então, eu acho que as minhas dores estâo muito relacionadas com o lado psicológico (Violeta, 42 anos).

A gente aprende a ouvir o corpo da gente, dai eu passei a ouvir o corpo. A gente fica muito tensa, muito preocupada, vi que não adiantava aquilo, o psicológico que faz sentir a dor (Orquídea, 47 anos).

O espaço de diálogo que o Grupo da Coluna proporcionou, além da equipe de trabalho que se dispunha a tentar compreender os sentimentos, as dúvidas e as limitaçóes de cada participante, criava um ambiente de acolhimento que foi valorizado pelas participantes, como percebemos na fala de Violeta:

Ver as pessoas se importando comigo e com as minhas dores, isso ajuda muito, dá um ânimo pra continuar. Dá para ver que tem pessoas que estão tentando descobrir quais são as dores, o que se passa com cada pessoa, que cada pessoa é diferente da outra, que uma sente mais outra menos dor (Violeta, 42 anos).

Essa fala reforça a relevância de construirmos ações diferenciadas, voltadas para a construção de um serviço de saúde centrado nos usuários e suas necessidades e estabelecendo relaçóes entre trabalhadores e usuários que enfatizem o acolhimento e o vínculo (MACHADO et al., 2007; SOUZA et al., 2008). Atualmente, o maior compromisso das Políticas de Saúde é a humanização da saúde, que estimula a valorizaçáo dos sujeitos envolvidos no processo de produção da saúde, desde os usuários até os gestores (BRASIL, 2004). De acordo com a Política Nacional de Atenção Básica (BRASIL, 2012), o acolhimento do usuário é fundamental, sendo enfatizado que os profissionais investiguem as principais necessidades do usuário, inicialmente através da conversa e escuta, que são uma das alternativas para que um atendimento mais humanizado seja feito, questôes preconizadas nas aulas do Grupo da Coluna. Além disso, o atendimento embasado em parâmetros humanitários de solidariedade e de cidadania, onde os profissionais sejam capazes de recepcionar, atender, escutar, dialogar, tomar decisóes compartilhadas, amparar, orientar, negociar, é de grande importância para usuários que apresentam dor crônica, considerando que é um problema que causa uma tendência ao isolamento social e à depressão, gera sentimentos de angústia, descrença e desesperança (OLIVEIRA; GAZETTA; SALIMENE, 2004; SOUZA et al., 2008).

Acreditamos que os benefícios alcançados com o presente estudo se devem também à orientaçáo de tratamento utilizada: a abordagem biopsicossocial. Para dor musculoesquelética crônica, o entendimento biomédico do processo de saúde-doença é insuficiente, pois este vê apenas a doença em si, não levando em consideraçáo as questôes psicossociais. A medicalização como principal recurso terapêutico é uma característica marcante da abordagem biomédica, 
que pode resultar na diminuição da autonomia dos pacientes (GAUDENZI; ORTEGA, 2012; TESSER, 2006), o que é incongruente com a orientação das diretrizes e políticas de participação ativa do usuário na resolução do seu problema de saúde.

O manejo biopsicossocial da dor tem como objetivo principal ver além do problema físico, instigando a compreensão da experiência de vida e todas as questóes psicológicas e sociais envolvidas (MARCO, 2006). Este tipo de atendimento começou a ser discutido e desenvolvido, pois era intrínseco considerar as atividades de vida diária, os aspectos sociais, intelectuais, emocionais e culturais do paciente, além da queixa de dor (FAVA; SONINO, 2008). Essa forma de manejo da dor, apesar de exigir mais do profissional de saúde, tem resultados positivos, como observado no presente estudo, pois ela estimula o usuário a compreender o seu problema de saúde, entendendo quais são as repercussôes no seu cotidiano e os motivos pelos quais a mudança de hábitos é relevante. A abordagem educativa, que promove o acolhimento do usuário, recomendado pelas políticas de saúde brasileiras, faz com que o usuário sinta que o profissional de saúde está profundamente comprometido com seu problema, o que pode contribuir para adesão ao tratamento.

Apesar da repercussão positiva do Grupo, é importante considerar que ele foi relevante para aquelas participantes que se identificaram com a proposta e participaram da intervenção. Resultados referentes às usuárias que não se adaptaram são desconhecidos. Outros estudos nesse sentido são necessários, para que se possa conhecer os motivos da não adesão de algumas participantes.

\section{Conclusão}

O Grupo da Coluna ofereceu informações que estimularam as participantes a conscientizarem-se de suas limitaçóes, possibilitou entenderem a importância de manter uma postura adequada para evitar a recorrência de dores e ensinou exercícios terapêuticos que poderiam ajudar a administrar ou prevenir dores musculoesqueléticas, atuando como uma alternativa complementar no tratamento de dores musculoesqueléticas crônicas.

As falas das participantes do estudo indicam que esse conjunto de recursos educativos lhes ajudou a encontrar formas de lidar melhor com tarefas domésticas, sejam elas realizadas como rotina da vida privada ou como atividade laboral, e contribuiu para que tivessem maior autonomia no autocuidado. O Grupo também propiciou um ambiente de acolhimento e ampliou a rede de relações e interações sociais, ajudando-as a lidar com um período de fragilidade e com tendência ao isolamento, gerando, além de uma melhora da capacidade funcional, um melhora da autoestima e do enfrentamento das adversidades decorrentes da dor crônica.

Estudos, tanto quantitativos quanto qualitativos, que avaliem os serviços prestados em atenção básica em saúde são essenciais para que se verifique se eles auxiliam na melhora da saúde dos usuários. No entanto, no âmbito da dor e dos hábitos posturais no contexto do SUS, ainda são escassos os estudos qualitativos, que têm um papel importante na exploração de questóes mais subjetivas relacionadas à dor e percepçóes dos seus participantes.

No presente estudo, a partir dos depoimentos nas entrevistas, foi possível entender o que sensibiliza e atinge as participantes e de que forma elas lidam com as informaçóes que adquirem. Essas percepçōes também auxiliam no sentido de permitir que os ministrantes do programa possam investir ou modificar determinados aspectos dos encontros do Grupo da Coluna quando necessário. Os diferentes programas de Escola Postural apresentados na literatura têm por objetivo facilitar a aquisição de hábitos posturais saudáveis, principalmente no que se refere às atividades de vida diária, através de orientaçóes sobre a anatomia da coluna, movimentos que favorecem a estrutura corporal e exercícios que aliviam a dor e melhoram a capacidade funcional. Os resultados do presente estudo demonstram que este objetivo foi alcançado.

Conclui-se, portanto, que o Grupo da Coluna se mostrou benéfico por influenciar de forma positiva o cotidiano das usuárias e conscientizá-las da importância das relaçôes interpessoais e da adoção de hábitos de vida mais saudáveis. A abordagem educativa da postura, visando uma melhora da funcionalidade na execução de atividades de vida diária pode, portanto, ser considerado um programa compatível com os objetivos das políticas nacionais de atenção à saúde e ministrado por diferentes profissionais que atuam na atenção básica à saúde. As falas das participantes demonstraram a relevância do cuidado humanizado, pautado pelo acolhimento e pela escuta de experiências de vida e de questóes psicossociais, para promover a saúde e permitir uma visão mais ampla do processo de adoecimento, contribuindo para uma melhora da qualidade de vida.

\section{Referências}

AIRAKSINEN, O. et al. Chapter 4. European guidelines for the management of chronic nonspecific low back pain. European Spine Journal, Neuenegg, v. 15, p. 192-300, 2006. Suplemento 2. 
ALVES, L. C. et al. A influência das doenças crônicas na capacidade funcional dos idosos do Município de Sáo Paulo, Brasil. Cadernos de Saúde Pública, Rio de Janeiro, v. 23, n. 8, p. 1924-1930, 2007.

ANDRADE, S. C.; ARAÚJO, A. G. R.; VILAR, M. J. P. "Escola de coluna”: revisão histórica e sua aplicação na lombalgia crônica. Revista Brasileira de Reumatologia, São Paulo, v. 45, n. 4, p. 224-228, 2005.

ANDRÉ, M. E. D. A. Texto, contexto e significado: algumas questốes na análise de dados qualitativos. Cadernos de Pesquisa, São Paulo, n. 45, p. 66-71, 1983.

ARCANJO, G. N.; VALDÉS, M. T. M.; SILVA, R. M. Percepçáo sobre qualidade de vida de mulheres participantes de oficinas educativas para dor na coluna. Ciência \& Saúde Coletiva, Rio de Janeiro, v. 13, n. 2, p. 2145-2154, 2008.

BALAGUÉ, F. et al. Non-specific low back pain. The Lancet, London, v. 379, n. 9814, p. 482-491, 2012.

BORGES, R. G. et al. Efeitos da participação em um Grupo de Coluna sobre as dores musculoesqueléticas, qualidade de vida e funcionalidade dos usuários de uma Unidade Básica de Saúde de Porto Alegre. Motriz, Rio Claro, v. 17, n. 4, p. 719-727, 2011.

BRASIL. Ministério da Saúde. Secretaria-Executiva. Núcleo Técnico da Política Nacional de Humanização. Humaniza SUS: Política Nacional de Humanização: a humanização como eixo norteador das práticas de atenção e gestão em todas as instâncias do SUS. Brasília, 2004. Disponível em: <http://bvsms.saude.gov.br/bvs/publicacoes/humanizasus_2004.pdf>. Acesso em: 10 fev. 2016.

BRASIL. Ministério da Saúde. Secretaria de Vigilância à Saúde. Secretaria de Atenção à Saúde. Diretrizes e recomendaçôes cuidado integral de doenças crônicas não-transmissiveis: promoção da saúde, vigilância, prevenção e assistência. Brasília, 2008. Disponível em: <http://bvsms.saude.gov. br/bvs/.../diretrizes_recomendacoes_cuidado_doencas_cronicas.pdf>. Acesso em: 12 out. 2016.

BRASIL. Ministério da Saúde. Política Nacional de Promoção da Saúde. Brasília, 2010. Disponível em: <http://bvsms. saude.gov.br/bvs/publicacoes/politica_nacional_promocao_saude_3ed.pdf>. Acesso em: 10 fev. 2016.

BRASIL. Ministério da Saúde. Secretaria de Vigilância em Saúde. Departamento de Análise de Situação de Saúde. Plano de açóes estratégicas para o enfrentamento das doenças crônicas não transmissiveis (DCNT) no Brasil 2011-2022. Brasília, 2011. Disponível em: < http:// bvsms.saude.gov. br/bvs/publicacoes/plano_acoes_enfrent_dcnt_2011.pdf $>$. Acesso em: 12 out. 2016.

BRASIL. Secretaria de Atenção à Saúde. Departamento de Atenção Básica. Política Nacional de Atenção Básica. Brasília, 2012. Disponível em: < http://189.28.128.100/dab/docs/ publicacoes/geral/pnab.pdf>. Acesso em: 10 fev. 2016.

BRASIL. Ministério da Saúde. Secretaria de Atenção à Saúde. Departamento de Atenção Básica. Diretrizes para o cuidado das pessoas com doenças crônicas nas redes de atenção à saúde e nas linhas de cuidado prioritárias. Brasília,
2013. Disponível em: <http:// bvsms.saude.gov.br/bvs/.../ diretrizes\%20_cuidado_pessoas\%20_doencas_cronicas. pdf>. Acesso em: 12 out. 2016.

BRASIL. Ministério da Saúde. Secretaria de Atenção à Saúde. Departamento de Atenção Básica. Estratégias para o cuidado da pessoa com doença crônica. Brasília, 2014a. Disponível em: <http:// bvsms.saude.gov.br/bvs/.../estrategias_cuidado_pessoa_doenca_cronica_cab35.pdf $>$. Acesso em: 12 out. 2016.

BRASIL. Ministério da Saúde. Secretaria de Atenção à Saúde. Departamento de Atenção Básica. Núcleo de Apoio à Saúde da Família. Brasília, 2014b. Disponível em: <http://189.28.128.100/dab/docs/portaldab/publicacoes/ caderno_39.pdf >. Acesso em: 12 out. 2016.

CHOU, R. et al. Diagnosis and treatment of low back pain: a joint clinical practice guideline from the American College of Physicians and the American Pain Society. Annals of Internal Medicine, Philadelphia, v. 147, n. 7, p. 478-491, 2007.

FAVA, G. A.; SONINO, N. The biopsychosocial model thirty years later. Psychotherapy and Psychosomatics, Basel, v. 77 , n. 1, p. 1-2, 2008.

FAVORETO, C. A. O.; CABRAL, C. C. Narrativas sobre o processo saúde-doença: experiência em grupos operativos de educação em saúde. Interface - Comunicação, Saúde, Educação, Botucatu, v. 13, n. 28, p. 7-18, 2009.

FERGUSON, F. Dor lombar, desafios clínicos, pontos principais, estudos de caso. Rio de Janeiro: Elsevier, 2010.

FURTADO, R. et al. Validation of the Brazilian-Portuguese version of the gesture behavior test for patients with non-specific chronic low back pain. Clinics, São Paulo, v. 64, n. 2, p. 83-90, 2009.

GALHEIGO, S. M. O cotidiano na terapia ocupacional: cultura, subjetividade e contexto histórico social. Revista de Terapia Ocupacional da Universidade de São Paulo, São Paulo, v. 14, n. 3, p. 104-109, 2003.

GAUDENZI, P.; ORTEGA, F. O estatuto da medicalização e as interpretaçóes de Ivan Illich e Michel Foucault como ferramentas conceituais para o estudo da desmedicalização. Interface - Comunicação, Saúde, Educação, Botucatu, v. 16, n. 40, p. $21-34,2012$

GIORGI, A. Sobre o método fenomenológico utilizado como modo de pesquisa qualitativa nas ciências humanas: teoria, prática e avaliação. In: POUPART, J. et al. A pesquisa qualitativa: enfoques epistemológicos e metodológicos. Petrópolis: Vozes, 2008. p. 386-409.

GUEDES, B. N.; SILVA, M. I. T.; SILVA, C. C. A metodologia da problematizaçáo na Escola de Posturas da UFPB: um processo emancipatório na prática da educação gerontológica. Revista Eletrônica de Enfermagem, Goiânia, v. 9, n. 2, p. 298-314, 2007.

LIRA, G. V.; NATIONS, M. K.; CATRIB, A. M. F. Cronicidade e cuidados de saúde: o que a antropologia da saúde tem a nos ensinar? Texto \& Contexto - Enfermagem, Florianópolis, v. 1, n. 13, p. 147-155, 2004. 
MACHADO, M. F. A. S. et al. Integralidade, formação de saúde, educação em saúde e as propostas do SUS: uma revisão conceitual. Ciência \& Saúde Coletiva, Rio de Janeiro, v. 12, n. 2, p. 335-342, 2007.

MARCO, M. A. Do modelo biomédico ao modelo biopsicossocial: um projeto de educação permanente. Revista Brasileira de Educação Médica, Rio de Janeiro, v. 30, n. 1, p. 1-13, 2006.

MAUSS, M. Sociologia e Antropologia. São Paulo: EPU, 1974.

MENDES, E. V. O cuidado das condiçóes crônicas na atenção primária à saúde: o imperativo da consolidação da estratégia da saúde da família. Brasília: OPAS, 2012. Disponível em: <http://bvsms.saude.gov.br/bvs/publicacoes/cuidado_condicoes_atencao_primaria_saude.pdf $>$. Acesso em: 10 fev. 2016.

MINAYO, M. C. S. O desafio do conhecimento: pesquisa qualitativa em saúde. São Paulo: HUCITEC, 2010.

MORETTI, A. C. et al. Práticas corporais/atividade física e políticas públicas de promoção da saúde. Saúde \& Sociedade, São Paulo, v. 18, n. 2, p. 346-354, 2009.

NOLL, M. et al. Escolas posturais desenvolvidas no Brasil: revisão sobre os instrumentos de avaliação, as metodologias de intervenção e seus resultados. Revista Brasileira de Reumatologia, São Paulo, v. 54, n. 1, p. 51-58, 2014.

OLIVEIRA, E. S.; GAZETTA, M. L. B.; SALIMENE, A. C. M. Dor crônica sob a ótica dos pacientes da escola de postura da DMR HC FMUSP. Acta Fisiátrica, São Paulo, v. 11, n. 1, p. 22-26, 2004.

POLIZELLI, K. M.; LEITE, S. N. Quem sente é a gente, mas é preciso relevar: a lombalgia na vida das trabalhadoras do setor têxtil de Blumenau - Santa Catarina. Saúde \& Sociedade, São Paulo, v. 19, n. 2, p. 405-417, 2010.
SALLES, M. M.; MATSUKURA, T. S. Estudo de revisão sistemática sobre o uso do conceito de cotidiano no campo da terapia ocupacional no Brasil. Cadernos de Terapia Ocupacional da UFSCar, São Carlos, v. 21, n. 2, p. 265-273, 2013.

SILVA-ARIOLI, I. G. et al. Promoção e educação em saúde: uma análise epistemológica. Psicologia: Ciência e Profissão, Brasília, v. 33, n. 3, p. 672-687, 2013.

SOUZA, E. C. F. et al. Acesso e acolhimento na atenção básica. Cadernos de Saúde Pública, Rio de Janeiro, v. 24, p. 100-110, 2008. Suplemento 1.

SOUZA, J. L.; VIEIRA, A. Escola postural: um caminho para o conhecimento de si e o bem-estar corporal. Movimento, Porto Alegre, v. 9, n. 3, p. 101-122, 2003.

TESSER, C. D. Social medicalization (II): biomedical limits and proposals for primary care clinics. Interface Comunicação, Saúde, Educação, Botucatu, v. 10, n. 20, p. 347-362, 2006.

VIEIRA, A. A escola postural sob a perspectiva da educação somática: a reformulação de um programa de extensão na ESEF/UFRGS. 2004. 225 f. Tese (Doutorado em Ciências do Movimento Humano) - Universidade Federal do Rio Grande do Sul, Porto Alegre, 2004.

VIEIRA, A. Escola postural na perspectiva da Educação Somática. In: BOLSANELLO, D. P. Em pleno corpo. Curituba: Juruá, 2008. p. 283-296.

VIEIRA, A.; SOUZA, J. L. Concepçóes de boa postura dos participantes da Escola Postural da ESEF/UFRGS. Movimento, Porto Alegre, v. 8, n. 1, p. 9-20, 2002.

WARSCHAUER, M. “Lazer e saúde”: as práticas corporais no sistema público de Santo André. 2008. 214 f. Dissertação (Mestrado em Estudos Socioculturais e Comportamentais da Educaçáo Física e Esporte) - Universidade de São Paulo, São Paulo, 2008.

\section{Contribuição dos Autores}

Adriane Vieira responsabilizou-se pela concepção, análise das informaçóes e escrita do artigo. Patrícia Thurow Bartz responsabilizou-se pela escrita e revisão do artigo. Márcia Cardoso da Jornada responsabilizou-se pela coleta de dados, análise das informaçóes e escrita do artigo. Todas as autoras aprovaram a versão final do texto.

\section{Fonte de Financiamento}

FAPERGS, CNPq.

\section{Notas}

${ }^{1} \mathrm{O}$ material desta pesquisa faz parte de um projeto aprovado pelo Comitê de Ética (nº100354), tendo sido cumprido todos os procedimentos éticos. 